\title{
Fabrication and characterization of beta-type tricalcium phosphate sintered body with phosphorus/sulphur-complex cations
}

\author{
Kazuaki HASHIMOTO ${ }^{1, \dagger}$, Akinao II $^{1}$, Tadashi FUJIMOTO ${ }^{1}$ and Hirobumi SHIBATA ${ }^{1}$ \\ ${ }^{1}$ Department of Applied Chemistry, Faculty of Engineering, Chiba Institute of Technology, \\ 2-17-1 Tsudanuma, Narashino, Chiba 275-0016, Japan
}

\begin{abstract}
The crystal structure of $\beta$-tricalcium phosphate $(\beta$-TCP), which is used as a bone replacement material, is known to have five crystallographically distinct positions for the $\mathrm{Ca}$ atom and three distinct positions for the $\mathrm{P}$ atom. In this paper, we have successfully synthesized a new $\beta$-type tricalcium phosphate (Na- $\beta$-TCP/S) with phosphorus/sulfur-complex cations by solid state reaction method. This was achieved by using $\mathrm{Ca}_{20} \mathrm{Na}_{2}\left(\mathrm{PO}_{4}\right)_{14}$ (Na- $\beta$-TCP) as a starting material, adjusting the $\mathrm{Ca}(4)$ site occupied by $\mathrm{Na}$ atoms to become vacancies, and simultaneously adjusting the same moles of $S$ atoms to the $P(1)$ site. The obtained sintered bodies became dense with increasing the sintering temperature. The grain growth of the sintered bodies was inhibited with increasing sulfur content. Although the solubility of Na- $\beta$-TCP was about half of that of $\beta$-TCP, the solubility of Na- $\beta$ TCP/S powder samples slightly increased with increasing sulfur content. These results indicate that Na- $\beta$-TCP/ $S$ can be prepared by controlling not only the amounts of vacancies in the structure but also the sinterability and solubility of $\mathrm{Na}-\beta$-TCP/S due to the substitution of phosphorus and sulfur, and that Na- $\beta$-TCP/S has potential as a new $\boldsymbol{\beta}$-TCP material for bioceramics.

(02022 The Ceramic Society of Japan. All rights reserved.
\end{abstract}

Key-words : $\beta$-Tricalcium phosphate, Phosphorus/sulfur-complex cations, Sintered body, Solubility

[Received July 9, 2021; Accepted October 25, 2021]

\section{Introduction}

Beta-tricalcium phosphate $\left[\beta-\mathrm{Ca}_{3}\left(\mathrm{PO}_{4}\right)_{2}: \beta\right.$-TCP $]$ has been used clinically as a bone filler because of its excellent biocompatibility and bone replacement properties. ${ }^{1), 2)}$ When such calcium phosphate materials are used as biomaterials, it is considered ideal that the rate of bone resorption in vivo is approximately equal to the rate of bone formation. However, $\beta$-TCP has a high rate of resorption in vivo and its mechanical strength is lower than that of autogenous bone, which raises the risk of refracture.

$\beta$-TCP belongs to the rhombohedral system in the space group $R 3 c$, and its lattice parameters are $a=b=1.0435$ $\mathrm{nm}, c=3.7403 \mathrm{~nm}, \alpha=\beta=90^{\circ}, \gamma=120^{\circ}$ in the hexagonal setting. ${ }^{3)} \beta$-TCP has two crystallographically independent columns, $\mathrm{A}$ and $\mathrm{B}$, consisting of $\mathrm{Ca}$ polyhedral and $\mathrm{PO}_{4}$ tetrahedra, in the unit lattice, and these two columns are parallel to the $c$-axis; the A column is on the $c$-axis (3-fold rotation axis), and the $\mathrm{P}(1)-\mathrm{Ca}(4)-\mathrm{Ca}(5)-\mathrm{P}(1)-$ $\mathrm{Ca}(4)-\mathrm{Ca}(5)$ repetition. The $\mathrm{Ca}(4)$ site has an atomic occupancy of about 0.5 , and $\mathrm{A}$ column has a unique crystal

Corresponding author: K. Hashimoto; E-mail: kazuaki. hashimoto@it-chiba.ac.jp

\$ Preface for this article: Dol http://doi.org/10.2109/jcersj2. 130.P1-1 structure with vacancies. On the other hand, B column consists of a repetition of $\mathrm{P}(3)-\mathrm{Ca}(1)-\mathrm{Ca}(3)-\mathrm{Ca}(2)-\mathrm{P}(2)$, but the arrangement of the three Ca sites is not in a straight line but in a broken line. It is known that the substitution of various cations in $\beta$-TCP occurs mainly in relation to the $\mathrm{Ca}(4)$ and $\mathrm{Ca}(5)$ sites of the A column. Our research group has reported that the substitutional solid solution of various ions ${ }^{4)}$ in the calcium sites in the crystal structure of $\beta$ TCP improved its mechanical strength ${ }^{5)}$ and thermal structural stability, ${ }^{6}$ and also controlled its solubility. ${ }^{7)}$ There are also many reports by other researchers. ${ }^{8-12)}$ However, there are not many studies on the substitution of various ions into the anionic position in $\beta$-TCP.

We focused on sulfur, which is also an essential element for the survival of living organisms. It is an important component of the essential amino acid methionine, and is also present in another amino acid, cysteine. Sulfur is not toxic in vivo. Sulfur in bone is found as sulfate in proteoglycans, which maintain a constant number of osteoblasts and osteoclasts. Sulfur is mainly a hexavalent cation in vivo and forms $\mathrm{SO}_{4}$ oxoate by coordination with oxygen, which may be substituted into $\mathrm{PO}_{4}$ in the crystal structure of $\beta$ TCP.

In this study, in order to clarify the mechanism of sulfur substitution, $\mathrm{Ca}_{20} \mathrm{Na}_{2}\left(\mathrm{PO}_{4}\right)_{14}(\mathrm{Na}-\beta$-TCP) was prepared as a starting material by substituting $\mathrm{Na}$ ions for $\mathrm{Ca}(4)$ containing vacancies in the crystal structure of $\beta$-TCP. ${ }^{6)}$ The 
preparation of $\beta$-TCP with phosphorus/sulfur-complex cations $(\mathrm{Na}-\beta$-TCP/S) was attempted by substituting sulfur ions for phosphorus ions and decreasing the amount of $\mathrm{Na}$ ions for charge compensation. The crystal structure of the obtained product was investigated, and its sintered bodies were fabricated and their properties were evaluated.

\section{Experimental procedure}

\subsection{Powder preparation of $\beta$-TCP with phos-} phorus/sulfur-complex cations

To prepare $\beta$-TCP with phosphorus/sulfur-complex cations $(\mathrm{Na}-\beta-\mathrm{TCP} / \mathrm{S})$ by solid state reaction method, ammonium dihydrogen phosphate $\left[\left(\mathrm{NH}_{4}\right) \mathrm{H}_{2} \mathrm{PO}_{4}\right.$; purity 99.9\%, FUJIFILM Wako Pure Chemicals, JAPAN] was used as phosphorus source, calcium oxide $(\mathrm{CaO}$; purity 99.9\%, FUJIFILM Wako Pure Chemicals, JAPAN) as calcium source, sodium nitrate $\left(\mathrm{NaNO}_{3}\right.$; purity $99.9 \%$, FUJIFILM Wako Pure Chemicals, JAPAN) as sodium source and ammonium sulfate $\left[\left(\mathrm{NH}_{4}\right)_{2} \mathrm{SO}_{4}\right.$; purity 99.95\%, FUJIFILM Wako Pure Chemicals, JAPAN] as sulfur source were used as starting materials, respectively.

The $(\mathrm{Ca}+\mathrm{Na}+\square) /(\mathrm{P}+\mathrm{S})$ molar ratio was kept constant at 1.571 , and the amount of sulfur added to the phosphorus position was increased by $\mathrm{S}$ mol $\%=\mathrm{S} /(\mathrm{P}+\mathrm{S})$. The samples were prepared by changing the amount of sulfur and sodium added by solid state reaction method (Table 1). The prepared samples were wet-mixed for $48 \mathrm{~h}$, and the resulting mixed powders were calcined in air at $1000{ }^{\circ} \mathrm{C}$ for $12 \mathrm{~h}$. The powders were identified by X-ray diffraction (XRD; MiniFlex 600, Rigaku, JAPAN), and Fourier transform infrared (FT-IR) absorption (FT-IR4200 , JASCO, JAPAN) by $\mathrm{KBr}$ method, and the lattice parameter was measured by the silicon internal standard method.

\subsection{Fabrication and evaluation of $\beta$-TCP sintered body with phosphorus/sulfur- complex cations}

The calcined powder described in the above section was added 2 vol \% PVA solution (5 wt.\%) and mesh classified to less than $75 \mu \mathrm{m}$. Furthermore, the powder added kerosin (5 wt.\%) was placed in a mold and was compacted to a size of ${ }^{\mathrm{L}} 45 \mathrm{~mm} \times \mathrm{W}_{2} 20 \mathrm{~mm} \times{ }^{\mathrm{t}} 5 \mathrm{~mm}$ by uniaxial pressing (CDM-20M, RIKEN KIKI, JAPAN) at the conditions of $57 \mathrm{MPa}$ for $1 \mathrm{~min}$. After molding, cold isostatic pressing (CIP) (Labo CIPLCP80-200A, NPA Co., Ltd., JAPAN) at $200 \mathrm{MPa}$ for $10 \mathrm{~min}$ was performed. The compacts were defatted at 380 and $500^{\circ} \mathrm{C}$ for $5 \mathrm{~h}$, and then sintered at $1100-1200^{\circ} \mathrm{C}$ for $24 \mathrm{~h}$. The sintered bodies were examined by the Archimedes method for the measurement of porosity and bulk density, and the microstructure was observed using a scanning electron microscope (VE-7800, KEYENCE, JAPAN).

\subsection{Evaluation of solubility of $\beta$-TCP with phosphorus/sulfur-complex cations}

A $0.08 \mathrm{~mol} \mathrm{~L}^{-1}$ acetic acid solution was prepared using acetic acid (purity $99.9 \%$, FUJIFILM Wako Pure Chemicals, JAPAN) and a $0.08 \mathrm{~mol} \mathrm{~L}^{-1}$ sodium acetate solution was prepared using sodium acetate (purity $98.5 \%$, FUJIFILM Wako Pure Chemicals, JAPAN). Each solution was mixed to $\mathrm{pH} 5.50 \pm 0.02$ using a $\mathrm{pH}$ meter (F-32, HORIBA, JAPAN) to prepare a $0.08 \mathrm{~mol} \mathrm{~L}^{-1}$ acetic acidsodium acetate buffer solution. After pouring $60 \mathrm{ml}$ of the $0.08 \mathrm{~mol} \mathrm{~L}^{-1}$ acetic acid-sodium acetate buffer solution into a polyethylene bottle, a $\mathrm{Ca}$ ion electrode was inserted, and $0.10 \mathrm{~g}$ of the sample was placed in the bottle while stirring at $430 \pm 15 \mathrm{rpm}$ to measure the amount of $\mathrm{Ca}$ ions dissolved from Na- $\beta-\mathrm{TCP} / \mathrm{S}$.

\section{Results and discussion}

\subsection{Substitutional solid solution mechanism of $\beta$-TCP with phosphorus/sulfur- complex cations}

The XRD of $\beta$-TCP with sulfur/phosphorus complex cation $(\mathrm{Na}-\beta$-TCP/S) obtained in this paper is shown in Fig. 1. It can be seen from the figure that the XRD of the sample with $\mathrm{Na}$ ions substituted at the $\mathrm{Ca}(4)$ position corresponds to the diffraction peak of the $\beta$-TCP structure (ICDD No. 055-0898), while the diffraction peaks of the byproducts HAp and $\alpha$-TCP are not observed. The diffraction peaks obtained were shifted to a slightly higher angle side, suggesting the formation of $\mathrm{Ca}_{20} \mathrm{Na}_{2}\left(\mathrm{PO}_{4}\right)_{14}$, which was the stoichiometric composition of the preparation. The diffraction peaks of all the samples obtained from the different formulations were exclusively due to the $\beta$-TCP structure. The specific diffraction peaks shifted to a lower angle with increasing sulfur content. This was suggested to be due to the formation of vacancies at the $\mathrm{Ca}(4)$ site, which is occupied by sodium in the crystal structure and the substitutional solid solution of sulfur at the phosphorus site.

The FT-IR spectra of $\mathrm{Na}-\beta$-TCP/S are shown in Fig. 2. It can be seen from the figure that the FT-IR spectrum of Na- $\beta$-TCP containing phosphorus shows four reference

Table 1. Formulation and chemical composition of $\mathrm{Na}-\beta$-TCP/S

\begin{tabular}{cccl}
\hline $\mathrm{S} /(\mathrm{P}+\mathrm{S}) \mathrm{mol} \%$ & $\mathrm{Na} /(\mathrm{Ca}+\mathrm{Na}+\square) \mathrm{mol} \%$ & $\square /(\mathrm{Ca}+\mathrm{Na}+\square) \mathrm{mol} \%$ & $\mathrm{Chemical} \mathrm{formula}$ \\
\hline 0 & 9.1 & 0 & $\mathrm{Ca}_{20} \mathrm{Na}_{2}\left(\mathrm{PO}_{4}\right)_{14}$ \\
2.0 & 7.8 & 1.3 & $\mathrm{Ca}_{20} \mathrm{Na}_{1.72} \square_{0.28}\left(\mathrm{PO}_{4}\right)_{13.71}\left(\mathrm{SO}_{4}\right)_{0.28}$ \\
4.0 & 6.6 & 2.5 & $\mathrm{Ca}_{20} \mathrm{Na}_{1.44} \square_{0.56}\left(\mathrm{PO}_{4}\right)_{13.44}\left(\mathrm{SO}_{4}\right)_{0.56}$ \\
6.0 & 5.3 & 3.8 & $\mathrm{Ca}_{20} \mathrm{Na}_{1.16} \square_{0.84}\left(\mathrm{PO}_{4}\right)_{13.16}\left(\mathrm{SO}_{4}\right)_{0.84}$ \\
8.0 & 4.0 & 5.1 & $\mathrm{Ca}_{20} \mathrm{Na}_{0.88} \square_{1.12}\left(\mathrm{PO}_{4}\right)_{12.88}\left(\mathrm{SO}_{4}\right)_{1.12}$ \\
10.0 & 2.7 & 6.4 & $\mathrm{Ca}_{20} \mathrm{Na}_{0.60} \square_{1.40}\left(\mathrm{PO}_{4}\right)_{12.60}\left(\mathrm{SO}_{4}\right)_{1.40}$ \\
12.0 & 1.5 & 7.6 & $\mathrm{Ca}_{20} \mathrm{Na}_{0.33} \square_{1.67}\left(\mathrm{PO}_{4}\right)_{12.33}\left(\mathrm{SO}_{4}\right)_{1.67}$ \\
14.3 & 0 & 9.1 & $\mathrm{Ca}_{20} \square_{2}\left(\mathrm{PO}_{4}\right)_{12}\left(\mathrm{PO}_{4}\right)_{12}\left(\mathrm{SO}_{4}\right)_{2}$ \\
\hline
\end{tabular}

$\square$ : Vacancy, $(\mathrm{Ca}+\mathrm{Na}+\square) /(\mathrm{P}+\mathrm{S}) \mathrm{mol}$ ratio $=1.571$. 


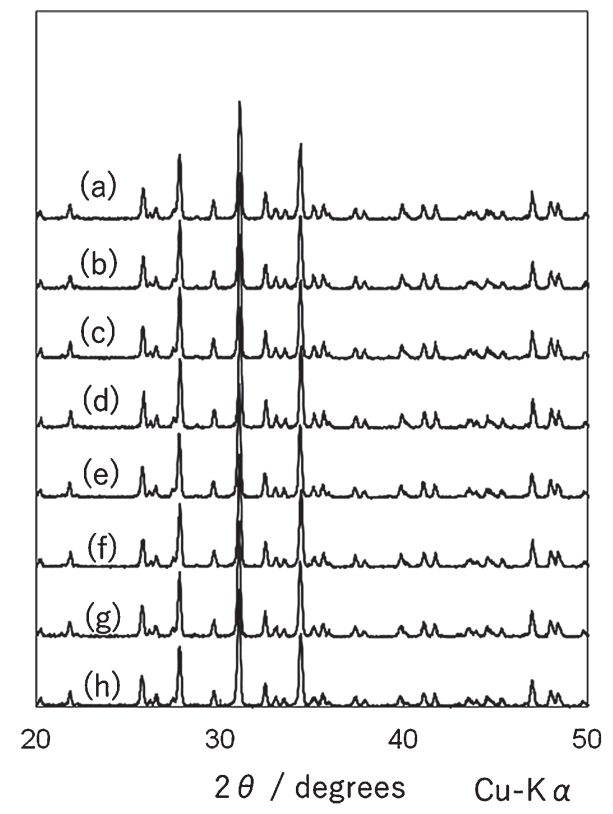

Fig. 1. XRD patterns of $\mathrm{Na}-\beta$-TCP/S. Sulfur content; (a) 0 mol $\%$, (b) $2.0 \mathrm{~mol} \%$, (c) $4.0 \mathrm{~mol} \%$, (d) $6.0 \mathrm{~mol} \%$, (e) $8.0 \mathrm{~mol} \%$, (f) $10.0 \mathrm{~mol} \%$, (g) $12.0 \mathrm{~mol} \%$, (h) $14.3 \mathrm{~mol} \%$.

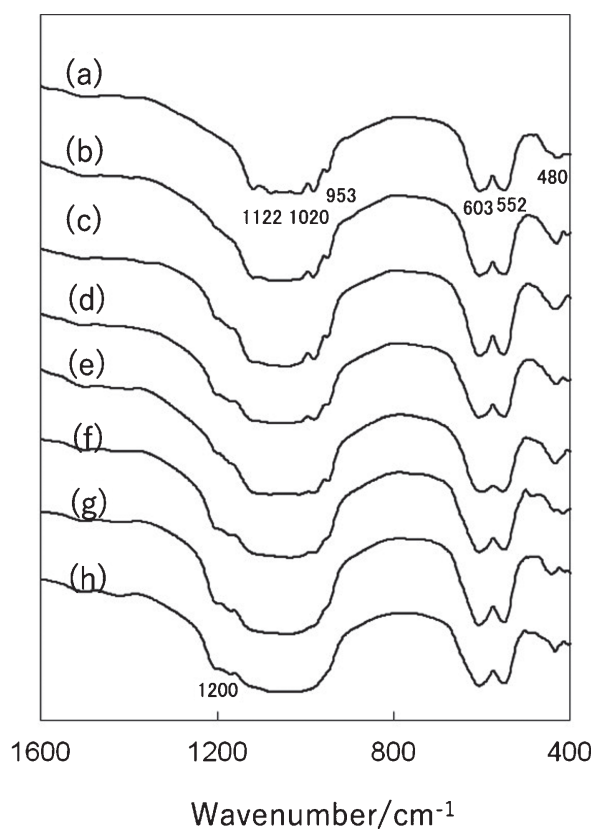

Fig. 2. FT-IR spectra of Na- $\beta$-TCP/S. Sulfur content; (a) 0 mol \%, (b) $2.0 \mathrm{~mol} \%$, (c) $4.0 \mathrm{~mol} \%$, (d) $6.0 \mathrm{~mol} \%$, (e) $8.0 \mathrm{~mol} \%$, (f) $10.0 \mathrm{~mol} \%$, (g) $12.0 \mathrm{~mol} \%$, (h) $14.3 \mathrm{~mol} \%$.

vibrations of $\mathrm{PO}_{4}$ group at around $1122 \mathrm{~cm}^{-1}\left(v_{3}\right), 1020$ $\mathrm{cm}^{-1}\left(v_{3}\right), 945 \mathrm{~cm}^{-1}\left(v_{1}\right), 603 \mathrm{~cm}^{-1}\left(v_{4}\right), 550 \mathrm{~cm}^{-1}\left(v_{4}\right)$ and $432 \mathrm{~cm}^{-1}\left(v_{2}\right)$. With the addition of sulfur, besides the absorptions attributed to the $\mathrm{PO}_{4}$ group, the absorptions attributed to the $\mathrm{SO}_{4}$ group were observed around 1200 $\mathrm{cm}^{-1}$ and the shoulder of the higher wavenumber of the absorption at $603 \mathrm{~cm}^{-1}$ and those peaks intensity increased with the increase in the amount of sulfur addition. These results mean that $\beta$-TCP containing both $\mathrm{PO}_{4}$ and $\mathrm{SO}_{4}$ was produced in the prepared sample.

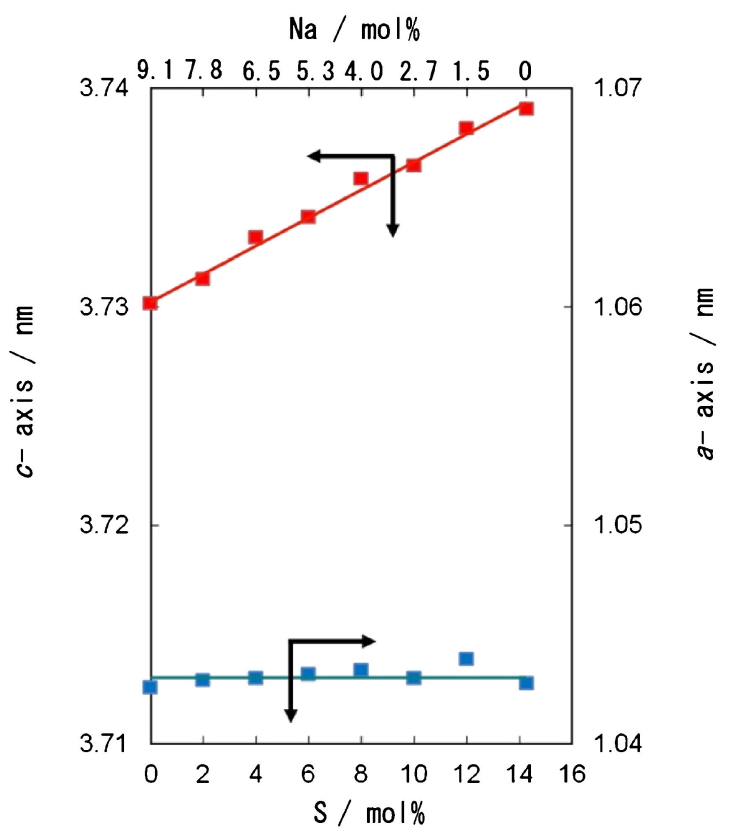

Fig. 3. Changes in lattice parameters of $\mathrm{Na}-\beta-\mathrm{TCP} / \mathrm{S}$ with sulfur content.

The lattice parameter of $\mathrm{Na}-\beta-\mathrm{TCP} / \mathrm{S}$ with respect to the amount of sulfur added is shown in Fig. 3. It can be seen from the figure that the $a$-axis was constant regardless of the amount of sulfur added, while the $c$-axis increased linearly with the amount of sulfur added up to $14.3 \mathrm{~mol} \%$. The reason for the constant $a$-axis is that the $\mathrm{SO}_{4}$ tetrahedron (average bond distance: $0.149 \mathrm{~nm}$ ) substituted for the $\mathrm{PO}_{4}$ tetrahedron (average bond distance: $0.154 \mathrm{~nm}$ ) also has a comparable interbond distance. On the other hand, the reason for the linear increase in the $c$-axis is that the positively charged $\mathrm{Na}$ ion at the $\mathrm{Ca}(4)$ site changes to vacancy, weakening the bond with the $\mathrm{PO}_{4}$ tetrahedron just above the $\mathrm{Ca}(4)$ site, which causes expansion along the $c$-axis. From the above results, it can be concluded that the chemical composition of the obtained sample can be expressed as $\mathrm{Ca}_{20} \mathrm{Na}_{2-x} \square_{x}\left(\mathrm{PO}_{4}\right)_{14-x}\left(\mathrm{SO}_{4}\right)_{x}(0<x<2, \square$ : vacancy), because the sulfur ion is substituted in the $\mathrm{P}(1)$ site up to $14.3 \mathrm{~mol} \%$ in the $\beta$-TCP structure, and the Na ions in the $\mathrm{Ca}(4)$ sites are changed to vacancies for the charge compensation.

\subsection{Evaluation of $\beta$-TCP sintered body with sulfur/phosphorus-complex cations}

The change in the volumetric shrinkage of Na- $\beta$-TCP/S compacts before and after sintering is shown in Fig. 4. It can be seen that the change of volumetric shrinkage before and after sintering was not so large at the sintering temperature of $1100^{\circ} \mathrm{C}$. The volumetric shrinkage increased with the increase of sulfur addition under the condition of sintering temperature of $1150^{\circ} \mathrm{C}$, suggesting the progress of sintering. The volumetric shrinkage was larger than that at $1150^{\circ} \mathrm{C}$ suggesting that the sintered bodies became dense at a sintering temperature of $1200^{\circ} \mathrm{C}$. These results indicate that the sintering reaction of $\mathrm{Na}-\beta-\mathrm{TCP} / \mathrm{S}$ occurs significantly above $1150^{\circ} \mathrm{C}$. 


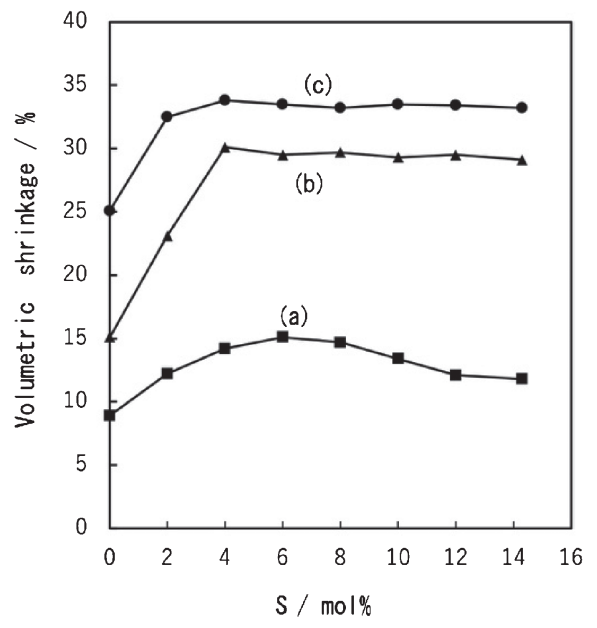

Fig. 4. Change in volume shrinkage of $\mathrm{Na}-\beta$-TCP/S compacts before and after sintering. Sintering temperature; (a) $1100^{\circ} \mathrm{C}$, (b) $1150{ }^{\circ} \mathrm{C}$, (c) $1200^{\circ} \mathrm{C}$.
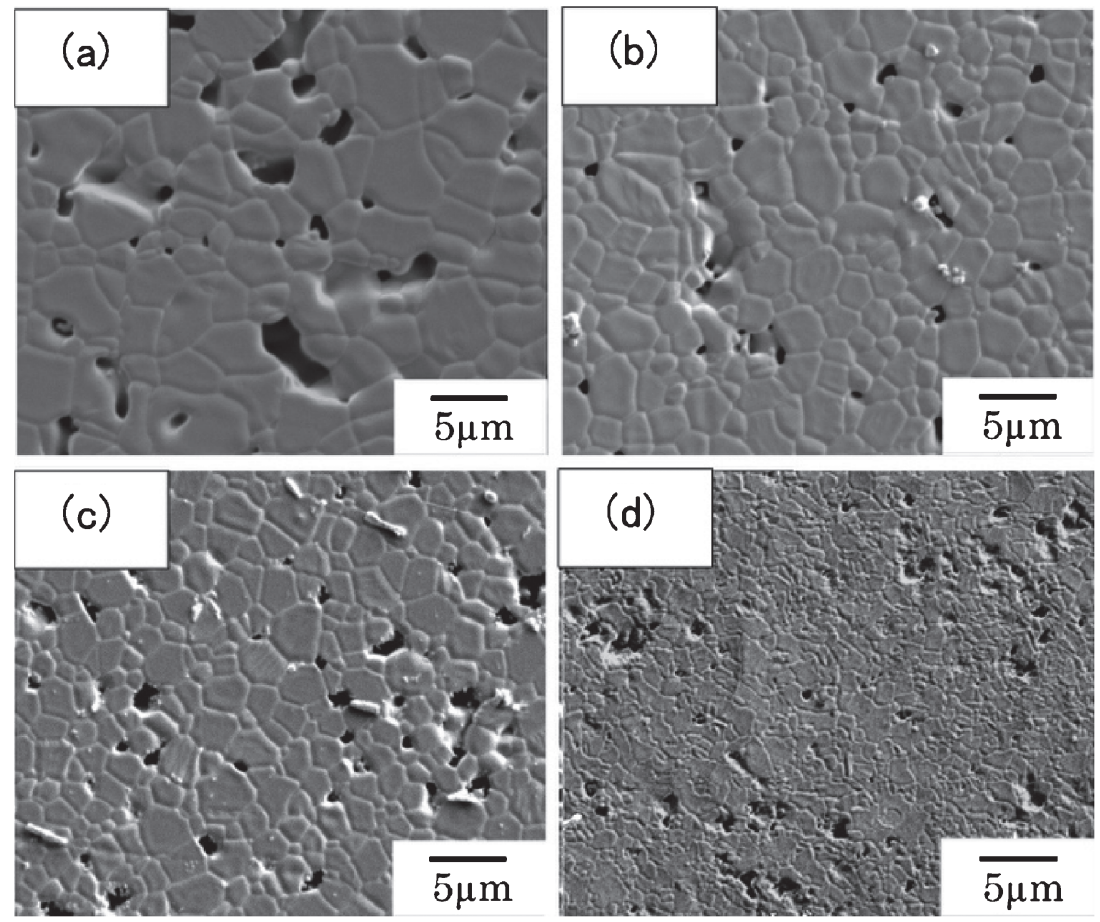

Fig. 6. SEM image of $\mathrm{Na}-\beta-\mathrm{TCP} / \mathrm{S}$ sintered body at $1150^{\circ} \mathrm{C}$. Sulfur content; (a) $0 \mathrm{~mol} \%$, (b) $6.0 \mathrm{~mol} \%$, (c) $10.0 \mathrm{~mol} \%$, (d) $14.3 \mathrm{~mol} \%$.

The changes in open porosity and bulk density of $\mathrm{Na}-\beta$ $\mathrm{TCP} / \mathrm{S}$ sintered body are shown in Fig. 5. It can be seen that the sintered bodies did not occur much densification and grain growth at the sintering temperature of $1100^{\circ} \mathrm{C}$, even though the amount of sulfur was changed, because the sintering was in the early stage. The densification of sintering progressed with increasing sulfur content at a sintering temperature of $1150^{\circ} \mathrm{C}$. This was probably due to the evacuation of internal pores and the shrinkage of the compact. However, the grain growth of the sintered body was inhibited with increasing sulfur content. The densification and inhibition of grain growth became more remarkable when the sintering temperature was increased

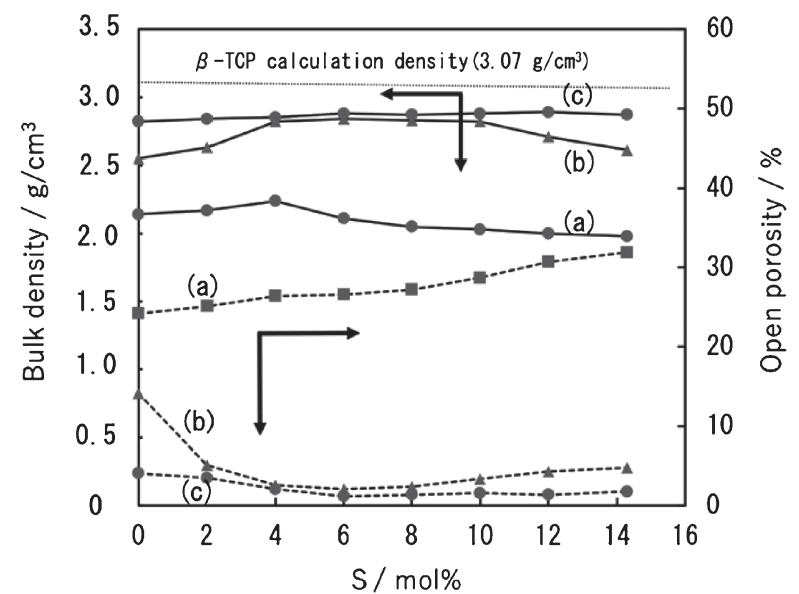

Fig. 5. Changes in open porosity (dotted line) and bulk density (solid line) of $\mathrm{Na}-\beta$-TCP $/ \mathrm{S}$ sintered body. Sintering temperature; (a) $1100^{\circ} \mathrm{C}$, (b) $1150^{\circ} \mathrm{C}$, (c) $1200^{\circ} \mathrm{C}$. to $1200^{\circ} \mathrm{C}$. In particular, the sintered bodies with the highest bulk density were obtained when the sulfur content was between 4 and $10 \mathrm{~mol} \%$. It was found that $\mathrm{Na}-\beta$-TCP/ $\mathrm{S}$ could be sintered at $1200^{\circ} \mathrm{C}$ without alpha-formation, while pure $\beta$-TCP would be partially alpha-formed when sintered at $1150{ }^{\circ} \mathrm{C}$ for a long time. This suggests that the structural stability of $\mathrm{Na}-\beta-\mathrm{TCP} / \mathrm{S}$ is improved at high temperature compared with that of pure $\beta$-TCP.

SEM microstructural images of $\mathrm{Na}-\beta-\mathrm{TCP} / \mathrm{S}$ sintered bodies at sintering temperatures of 1150 and $1200{ }^{\circ} \mathrm{C}$ are shown in Figs. 6 and 7, respectively. The specimens were prepared by mirror polishing, thermal etching at $1050{ }^{\circ} \mathrm{C}$ for $3 \mathrm{~h}$, and gold deposition. The sintered bodies became 

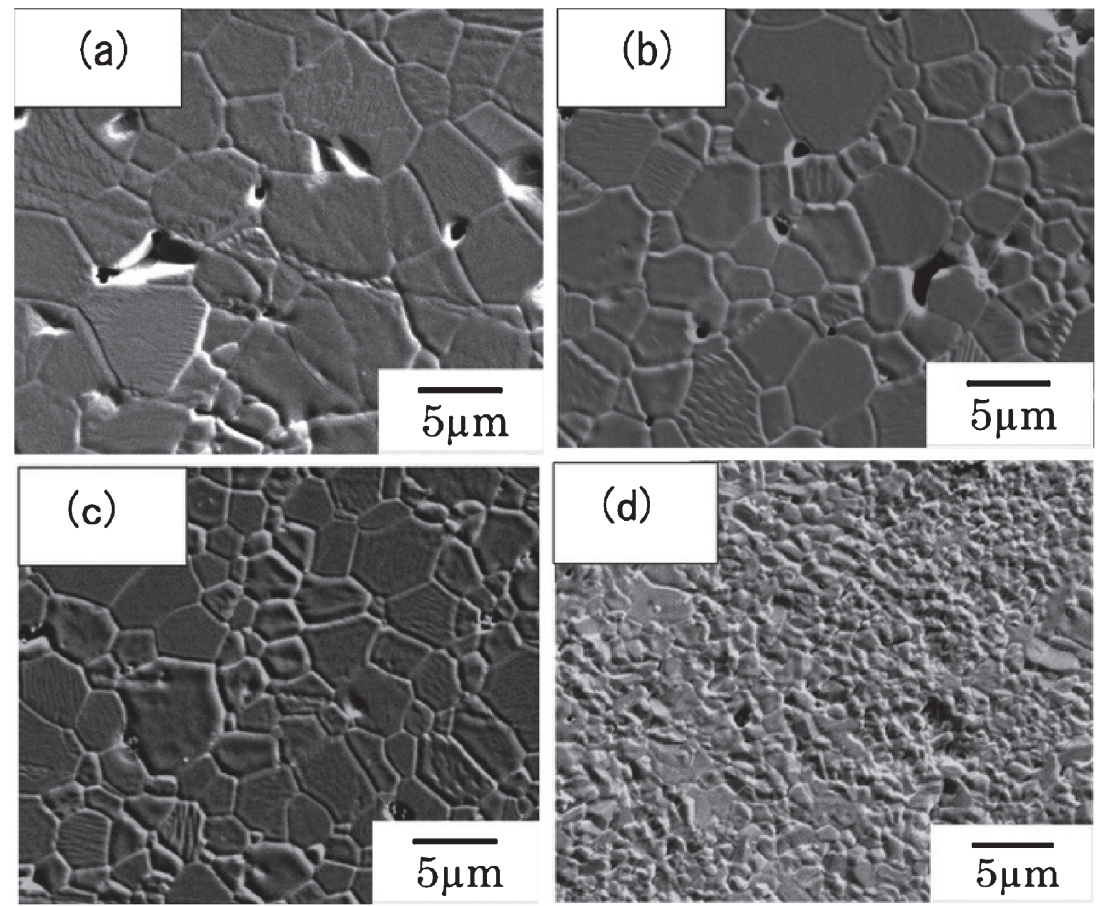

Fig. 7. SEM image of $\mathrm{Na}-\beta-\mathrm{TCP} / \mathrm{S}$ sintered body at $1200^{\circ} \mathrm{C}$. Sulfur content; (a) $0 \mathrm{~mol} \%$, (b) $6.0 \mathrm{~mol} \%$, (c) $10.0 \mathrm{~mol} \%$, (d) $14.3 \mathrm{~mol} \%$.

denser with increasing sulfur content at the sintering temperature of $1150^{\circ} \mathrm{C}$ and the grain growth was inhibited. In particular, the sintered bodies with the high bulk density were obtained when the sulfur content was 6 and 10 mol \%. The grain growth and densification of the sintered bodies at the sintering temperature of $1200^{\circ} \mathrm{C}$ are more progressed than those at $1150^{\circ} \mathrm{C}$.

\subsection{Evaluation of solubility of $\beta$-TCP with phosphorus/sulfur-complex cations}

The solubility of calcium phosphate powder in vitro was evaluated. ${ }^{13)}$ The $\mathrm{Ca}$ ion concentration of pure $\beta$-TCP was $4.05 \mathrm{mM}$ after $30 \mathrm{~min}$, and that of Na- $\beta$-TCP was $1.55 \mathrm{mM}$ after $30 \mathrm{~min}$. Compared with $\beta$-TCP, the solubility of Na$\beta$-TCP was reduced to about $40 \%$. Substitution of $\mathrm{Na}$ ions into $\mathrm{Ca}(4)$ sites of $\beta$-TCP structure decreased the solubility, because substitution of $\mathrm{Na}$ ions into $\mathrm{Ca}(4)$ sites (occupancy 0.5 ) improved the thermal stability of $\beta$-TCP structure. We have already reported on this in a previous paper. ${ }^{6,7)}$

Figure 8 shows the change of $\mathrm{Ca}$ ion concentration from $\mathrm{Na}-\beta$-TCP/S with sulfur contents. The solubility of $\mathrm{Na}-\beta$ $\mathrm{TCP} / \mathrm{S}$ gradually increased with the increase of sulfur addition, and the $\mathrm{Ca}$ ion concentration of $\mathrm{Ca}_{20} \square_{2}\left(\mathrm{PO}_{4}\right)_{12}\left(\mathrm{SO}_{4}\right)_{2}$ $(\beta$-TCP/S) with $14.3 \mathrm{~mol} \%$ sulfur was $2.0 \mathrm{mM}$ after 30 $\min$. However, this value was sufficiently low compared to pure $\beta$-TCP. The solubility of a substance is expressed by the equation $\Delta G=R T \ln K s p$, and it is known that as $\Delta G$ decreases, the $K s p$ value also decreases. In other words, when the amount of sulfur in the phosphorus site of $\mathrm{Na}-\beta$ TCP was increased and the amount of sodium in the $\mathrm{Ca}(4)$ site was decreased, vacancies were induced in the $\mathrm{Ca}(4)$

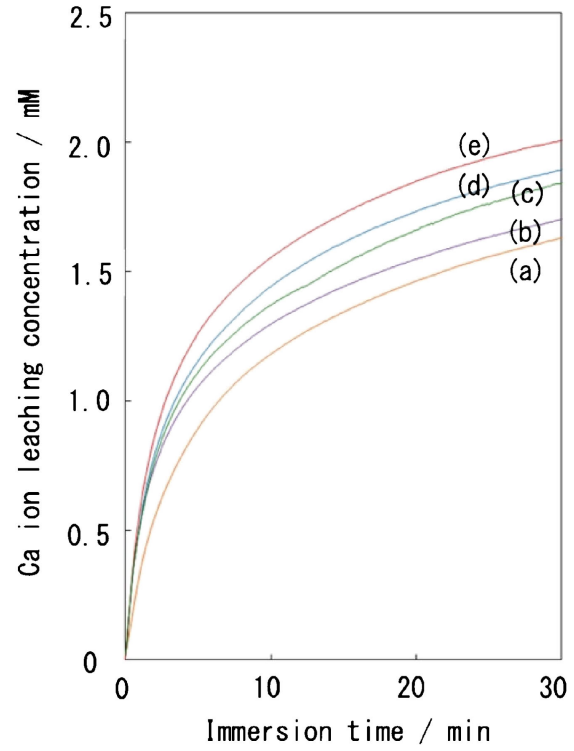

Fig. 8. Change in $\mathrm{Ca}$ ion concentration from $\mathrm{Na}-\beta-\mathrm{TCP} / \mathrm{S}$ with sulfur contents. Sulfur content; (a) $0 \mathrm{~mol} \%$, (b) $4.0 \mathrm{~mol} \%$, (c) 8.0 $\mathrm{mol} \%$, (d) $12.0 \mathrm{~mol} \%$, (e) $14.3 \mathrm{~mol} \%$.

site. We speculated that the formation of these vacancies slightly reduced the thermal stability and slightly increased the solubility of $\beta$-TCP/S compared to Na- $\beta$-TCP.

\section{Conclusion}

$\mathrm{Na}-\beta-\mathrm{TCP} / \mathrm{S}$ was successfully prepared by substituting sodium for calcium and sulfur for phosphorus based on the $\beta$-TCP structure by solid state reaction method, and at the same time, reducing the sodium to introduce vacancies for 
charge compensation. The grain growth of Na- $\beta$-TCP/S sintered compacts was inhibited with increasing sulfur content, and dense sintered bodies were successfully obtained at sulfur contents of $4-10 \mathrm{~mol} \%$. The solubility of Na- $\beta$-TCP/S was sufficiently low compared with that of pure $\beta$-TCP, indicating the possibility of using Na- $\beta$-TCP/ $\mathrm{S}$ as $\beta$-TCP ceramics for biomaterials with a new composition. We found that $\mathrm{Na}-\beta$ - TCP/S can control the sintering and solubility compared with Na- $\beta$-TCP and pure $\beta$-TCP not only by replacing sulfur with phosphorus but also by controlling the amounts of vacancies in the structure.

Acknowledgement This work was partially supported by the JSPS KAKENHI grant number 25350554 and grant number JP20K09990.

\section{References}

1) S. V. Dorozhkin, Ceram. Int., 42, 6529-6554 (2016).

2) A. Bigi and E. Boanini, J. Appl. Biomater. Func., 15, 313-325 (2017).

3) M. Yashima, A. Sakai, T. Kamiyama and A. Hoshikawa, J. Solid State Chem., 175, 272-277 (2003).
4) K. Yoshida, H. Hyuga, N. Kondo, H. Kita, M. Sasaki, M. Mitamura, K. Hashimoto and Y. Toda, J. Am. Ceram. Soc., 89, 688-690 (2006).

5) N. Matsumoto, A. Yokokawa, K. Ohashi, K. Yoshida, K. Hashimoto and Y. Toda, Phosphorus Res. Bull., 24, 73-78 (2010)

6) N. Matsumoto, K. Yoshida, K. Hashimoto and Y. Toda, J. Ceram. Soc. Jpn., 118, 451-457 (2010).

7) N. Matsumoto, K. Yoshida, K. Hashimoto and Y. Toda, Mater. Res. Bull., 44, 1889-1894 (2009).

8) R. Famery, N. Richard and P. Boch, Ceram. Int., 20, 327-336 (1994).

9) R. Enderle, F. Gotz-Neunhoeffer, M. Gobbels, F. A. Muller and P. Greil, Biomaterials, 26, 3379-3384 (2005).

10) S. Kannan, I. A. F. Lemos, J. H. G. Rocha and J. M. F. Ferreira, J. Solid State Chem., 178, 3190-3196 (2005).

11) K. Matsunaga, T. Kubota, K. Toyoura and A. Nakamura, Acta Biomater., 23, 329-337 (2015).

12) E. Boanini, M. Gazzano, C. Nervi, M. R. Chierotti, K. Rubini, R. Gobetto and A. Bigi, J. Funct. Biomater, 10, 20 (2019).

13) A. Ito, K. Senda, Y. Sogo, A. Oyane, A. Yamazaki and R. Z. LeGeros, Biomed. Mater., 1, 134-139 (2006). 